\title{
The Role of Teachers' Behaviour and Strategies in Managing a Classroom Environment
}

\author{
Priya Vijayan, Srikumar Chakravarthi, and John Arul Philips
}

\begin{abstract}
Managing a classroom is a challenge for teachers. Many factors have to be taken into consideration while planning and preparing for a new class of students. I feel that having a clear and consistent classroom management plan with an understanding of how the teacher will behave, the beliefs, the rules and strategies, are crucial in the running and organization of a classroom in order for all children to learn and succeed to the best of their ability.

The main aim of this case study is to look into how three themes (teacher behaviour, practical strategies and interventions and rules) appear in two classrooms in an International school in Malaysia. I used case study methodology by taking observations of what we have seen and how this relates back to the background research we have found. I have focused on the question: How do the themes of teacher behavior, the use of practical strategies and the use of rules affect the behavior management of a kindergarten and primary classroom in an International School in Malaysia?

My first classroom was based in a kindergarten class. My second classroom was in a standard two classroom. This paper is based upon findings of teachers of an early age range. The findings of this research showed that student-centered approach is crucial in the management of the classroom. However, the findings may not be universal due to children from different countries in the same classroom of an international school.
\end{abstract}

Index Terms-Classroom environment, strategies, management, teachers.

\section{INTRODUCTION AND RESEARCH QUESTION}

The research question of this paper was: How do the themes of teacher behaviour, the use of practical strategies and the use of rules affect the behavior management of a kindergarten and primary classroom in Malaysia?

I have explored the answer to this question through the use of case study methodology in a kindergarten classroom and a standard two classroom of an International School in Kuala Lumpur. I have found research to each main theme in the literature research/ review and backed each theme up with evidence. Overall I have three important themes that I wanted to research and find out more about. I will elaborate on each theme later in this paper.

During the course of the case study, I have explained the

Manuscript received August 6, 2014; revised October 29, 2014.

Priya Vijayan is with Segi University, Selangor, Malaysia (e-mail: priyasrikumar2012@gmail.com).

Srikumar Chakravarthi is with Perdana University, Selangor, Malaysia (e-mail: activedoctor@gmail.com).

John Arul Philip is the with School of Education, Asia e University, Kuala Lumpur, Malaysia (e-mail: john.arul@aeu.edu.my) . literature review with relevance to findings under each main themes and sub themes. I have looked in close detail at each theme within the literature review. Under each main theme I have then shown evidence and snapshots of what we have seen in the classrooms, and discussed each observation under each theme.

\section{LITERATURE REVIEW}

\section{A. Theme 1: Evidence on Teacher Behaviour: Classroom Management Style}

This very important theme, teacher behavior can affect a lot of different situations including the classroom environment, the way that staff and students respond to you and the overall behavior management within your classroom. Tteacher's behavior whether unconscious or conscious can affect the student's behavior [1]. Within this theme we will be looking closely at the management styles that teachers may use within their classrooms, teacher - student relationships and the labeling.

The teacher is an integral figure in the overall running and management of the classroom. "When teachers do not want to learn, it is obvious that the students are not going to learn either." [2] This suggests that the way in which the teacher plans and leads the classroom will have a dramatic effect on the student's academic achievement. If a teacher is not fully engaged and excited about what they are teaching then the children will pick up on this and not be engaged to learn as much as they could be. An effective teacher often becomes a professional leader who thinks, reflects and implements [2]. This leadership role has several qualities that will help to oversee the running of a classroom. Some of these qualities might include having plans, goals and vision, motivates and inspires others, works well with others, well prepared, passionate about what they are doing and focused.

\section{1) Teacher's management style}

Many teachers have different management styles that they prefer to use on a day-to-day basis. This will be due to individual preference, personality and values of the teacher. Levin and Nolan suggests that there are many different teaching strategies and management styles that teachers can use to promote good classroom management. They suggest three ways in which the class can be managed; student directed management, collaborative management and teacher directed management [1].

The purpose of the student directed approach is to build and create a community of learners in which they work 
productively together and care for one another. This would mean that in a collaborative classroom, the learning process is joint with student and teacher. Similar to the student directed approach; students are given a chance to control their own behavior. This gives students a chance to be responsible for their own learning process and behaviour [2]. Within a teacher directed management style classroom, the teacher will have sole responsibility for what is going on in the classroom and how the children are learning and behaving. This strategy could be helpful for some learning environments in which teacher direction is needed.

\section{2) Relationships affecting student behaviour}

The teacher-student relationships that are present and made within a classroom can have huge effects on the overall academic achievement and behavior management within a classroom. Teachers who are proficient and effective are more capable of impacting lives of students than teachers who are not proficient and effective [2]. Relationships are created between student and teacher in an effective classroom These relationships should be based on trust where the student feels comfortable. These relationships could be an important aspect of your student's lives not only within the classroom but also for the future. Students, especially at a young age need role models, someone to look up to who may influence their lives. It is highly important to make good connections with all of your students.

Effective classroom management and positive relationships between you and your students will produce a good environment for students to learn. The language in which you use will further affect the relationships you have with your students. The language which teachers use in can affect the relationship between student and teacher. [3] Teachers can often label students in terms of the language in which they use. This can be seen through descriptive or judgmental language that the teacher may use to address a student [2], [3].

\section{3) Labeling}

It is crucial to remember that the students within any classroom are unique individuals and respond in different ways. The positive relationships that you are hoping for may need some extra work with some students especially those with special needs or those with trust issues. Interacting well with all students is important if you want your class to be well managed. "Students who feel liked by their teachers reportedly have higher academic achievement and more productive classroom behavior than students who feel their teachers hold them in low regard." [4] This links in with teachers who have an unconscious label placed on a student. When a student believes that the teacher has placed this label upon them they may start to act upon this and behave in this way.

The way in which teachers perceive students can affect the way in which they behave. It was found that students who were labeled "at risk" performed better academically when these students were taught as if they were gifted. This surprising study showed that the teacher had already labeled the students to be "at risk" or "under achievers" [5].

\section{B. Theme 2: The Use of Practical Strategies}

There are numerous strategies and interventions that a teacher could use in order to maintain control and provide a good behaviour management system. "A strategy is an action taken by the teacher that is intended to stop the disruptive actions and return the student to the academic activities." [4] The strategy given should be based on the teacher's knowledge of what they know about the child, the action or misbehaviour issue and how often it occurs. I have decided to focus on three strategies in detail. These will be the "use of encouraging and reinforcing behavior", "the use of reward" and the "use of I messages". [4]

\section{1) Encouragement and positive reinforcement}

One of the most important factors in a well-run classroom is the use of encouragement and positive reinforcement. This strategy links in with the teacher's behaviour and beliefs. If a teacher has high expectations for all of their student's then positive encouragement, feedback and praise will come naturally and the students will often respect you for it and have an appreciation of learning and want to please you. When using positive reinforcement and encouraging the children to learn then the children will be motivated to do well. "The teacher serves as a powerful model in providing examples of ways for students to support each other with words of encouragement, questions for clarification and entry for collaboration" [6]. From this quote we can see the power the teacher has in order to create a positive and comfortable environment for the children to learn. Through the use of positive feedback and encouragement the students could start to model the practices of the teacher and may apply this to their own relationships with peers and others. This effective strategy is one that is crucial to students who need reassurance. If the teacher is constantly providing feedback and encouragement to all then an inclusive classroom will be built which will have many advantages for the future.

The aim of this theory is that after the teacher has recognized the negative behaviour, the teacher will be able to redirect the student's actions by using the same energy in positive rather than negative way.

\section{2) Giving suitable feedback and rewards}

The use of praise and positive reinforcement is one of the most important forms of reward, as praise can be satisfying to students and can affect the quantity and quality of the student's work and performance. The use of verbal praise and informative feedback can "allow students to receive satisfaction for the progress they have made so far, and is a much better way of rewarding rather than using threats or close monitoring" [4]. There are however many arguments against the use of praise and reward systems. It has been said by many that the over reliance and over use of verbal praise may become ineffective and unhelpful.

However surprising this is, many teachers still use this strategy throughout their teaching as a tool for creating a positive and manageable classroom environment. Ginott (1972) found that praise could be categorized into two types; appreciative praise and evaluative praise. When giving praise it is important that teachers do not evaluate personality or judge character [7]. This praise would be appreciative. This clearly shows that the use of praise as a type of reward should 
only be used if it is effective and makes a difference to the dynamics of the classroom and the behaviour that can be seen within it. Some examples given by Burden include rewards delivered in various ways such as -grades, spoken and written praise, activity rewards and special privileges (play games, use equipment), symbolic rewards (honour rolls, posting good papers), material rewards and teacher rewards (opportunities to work with teacher).

\section{Theme 3: Constructing Clear and Consistent Rules}

Well-constructed rules are essential to an efficient classroom environment and as a factor in reducing incidents of misbehavior. Levin and Nolan, (2010) state " Evidence indicates that children in general and children who exhibit disruptive behavior in particular are highly sensitive to changing situations and conditions. Given this, the need for rules is apparent." [1]

"Clear rules provide consistency in the classroom. Students prefer knowing the rules, consequences and rewards rather than having a teacher who arbitrarily changes or makes up new rules to fit the moment." [2]

Jones and Jones, (2004) also go on to suggest that helping students understand and accept classroom and whole school rules can provide benefit students and teaching [8].

Another important aspect, which relates to the development of rules in the classroom, is the use of self-monitoring techniques. Jones and Jones, (2004) suggest that rules should help students to choose appropriate behaviors rather than being used as a means of catching the student out misbehaving [8]. When a student misbehave teachers should discuss with the child about what they have done examining the motivation behind their actions and the consequences. This is a powerful technique to help students overcome behavioural issues because if students are encouraged to examine the motivations behind their behaviour as well as the consequences of their actions then they are less likely to dwell on the negative aspects of behavior [9]. This idea can be linked to the Jean Piaget's (1970) theory of children's moral development. Piaget proposed that children go through a number of different stages as the develop morality [10].

Encouraging moral development in children can be related to self-monitoring techniques in relation to classroom rules. From my experiences in school I have seen that this is a powerful way of managing behavior. This is because if you have a big class of children and you want them to work in groups on an activity it is very difficult to manage the behaviour of every group in the class, especially when you need to attend to their academic needs at the same time, Teaching them to control and monitor their own behavior can help them to become autonomous and will benefit them in their social development because if they are able to decide for themselves what is right and wrong then they are more likely to choose appropriate behaviours when socially interacting as well as preparing to become citizens in society by laying the foundation for future learning on law and justice [11].

Once an assessment of behaviour has been carried out the teacher must design materials for the students to self-monitor their behavior and then teach students how to use them effectively [11]. The materials could be something the students monitor their behaviour with such as reflection sheets, resources that the teacher uses to teach self-monitoring techniques (DVD's, worksheets, posters) or visible resources displayed around the classroom such as posters.

\section{METHODOLOGY}

The methods I chose to carry out were research on classroom management by using qualitative case studies. This included first hand observations of teaching practice, and document analysis from the school classrooms I observed. I chose this method of collecting because I felt it would help understand how the strategies I have discussed in this project were being implemented in the classroom. This allowed me to understand and explore them more deeply and observe first hand whether they were working or not.

My observation was in a kindergarten class and in standard two of a private International School in Kuala Lumpur. Both classrooms had female Indian teachers and 24 students each. The curriculum is established by the centre however, it is up to the teachers to decide the day-to-day routine and curriculum for the students. The teachers follow the Indian CBSE syllabus and plan their activities and lessons around these standards. The children are also assessed by these standards to see if they have met all of them by the end of the year. This integrated curriculum allows students to make connections between subjects and use the skills they have learnt in certain subjects and apply them to new situations in other subjects.

I have explained the literature review with relevance to findings under each main theme and sub themes. I have looked in close detail at each theme within the literature review. Under each main theme I have then shown evidence and snapshots of what we have seen in the classrooms, and discussed each observation under each theme.

\section{ANALYSIS}

\section{A. Theme One: Teacher Behavior in the Classroom}

As part of my observation, I noticed that in both classes, there was one teacher and one assistant and 24 students. Although there is a huge amount of collaboration and teamwork involved, the lead teacher oversees most of the decisions that need to be made.

Each teacher has their own individual way and style of teaching and it is therefore fascinating to see the differences in their approaches. One of the teachers is slightly older than another. You can tell that her approach to teaching is one that she has had for many years. She seems to be very consistent with the way she teaches. All of the lessons she teaches a very similar in structure.

Another teacher within the class is constantly using a variety of different and interactive activities to engage the children. Her method is collaborative, as she encourages the children to become involved with all lessons and reminds the children of the rules that they have made together. The difference between the two teachers is very clear, however each teacher is successful in their approach to learning, approach to teaching and their expectations of all the children 
within the class. I have observed both using a positive reinforcement and praise on a number of occasions and the students respond well to this. On one occasion I observed the teacher using praise at the beginning of a science lesson she reinforced the positive aspects of a previous lesson and explained her expectation that the students will do well in the science lesson she was teaching. I observed that the students responded really well to this praise and as a result the lesson was conducted with only minimal incidents of misbehavior.

It could be said that each teacher described takes on the Levin and Nolan approach of one management style at a time [1]. Their management style includes a mixture of student centered, collaborative and teacher directed. I have noticed that the students respond best to this approach as there is more excitement and variation in the style of teaching allowing for all learning needs to be met.

\section{1) Evidence on teacher - student relationships}

The relationships that are made between teacher and student within the preschool class are very important. My observations showed that the teachers make an extra effort to provide supportive, loving and caring relationships for all the students. The building of relationships and friendships is taught as soon as the children enter the classroom. If a child is upset, hurt, or shows any negative emotion the child is taken to one side, where they will discuss with the teacher what is wrong and the problem is usually resolved.

Constant contact with the parents is important too. The teachers have contact with the parents on a daily basis when the children are brought into school. A daily reflection letter is also sent home to the parents, which lets the parents know what has been going on during that day. This form of contact is appreciated by the parents, as they like to know what is going on in school and how their children are doing.

\section{2) Evidence on labeling and self-fulfilling}

Labeling is clearly linked to the positive relationships that are built between teacher and student. As an observer of the kindergarten class I have not seen much evidence of any labels being placed on children. The teachers have high expectations of all the students. Due to the varying ages and abilities of the children in the class the teachers have different but high expectations for each child depending on their age and level. The teachers will then work with the individual student to identify strengths and weaknesses and areas to work on. I do not feel like there is any negative labels attached to students that affect their overall achievement and learning and this is very positive to see. At this young age the children enjoy the attention and care the teachers give each child and this is a worthwhile approach and way of learning.

\section{B. Theme Two: The Use of Practical Strategies}

\section{1) Evidence on practical strategies}

The philosophy of discipline at the kindergarten is to work with the child and the family in a positive way. Negative behaviour is addressed by using appropriate techniques, which is always discussed between parents and teachers.

The following is a list of strategies, which is sent to parents to notify them what interventions and strategies will be used to deal with negative behaviour if it arises in the classroom.
These intervention strategies are used to ease the transition between home and school and try to limit negative behavior and also maintain positive behaviour.

\section{2) Encouraging and reinforcing positive behaviours}

This strategy seems to be used every day and in nearly every situation and part of the day to encourage the students to continue to do the very best that they can do. This strategy is often used as in individual positive reward of praise. The teachers often highlight a child's specific behavior or accomplishment. An example of this is the teacher praises the child for making a good choice or decision. This tells the child that they made the right choice in order to be noticed and praised by the teacher.

\section{3) Planned ignoring of negative behaviours}

Planned ignorance is most often used with younger aged children. I have seen it used mainly to avoid giving the children too much attention that they are craving from the teacher. This strategy is very age appropriate for preschool children as they transition from toddler and infant classrooms up to kindergarten they often have to share their attention between all the other children in the class. At this point the children are still learning the rules and procedures of the classroom and learning how to appropriately behave with all the other children in the class.

One example I have seen of planned ignorance of negative behaviours is of a new child that has just moved up to the standard two classes. This transition can be very difficult for some as the routines; rules and procedures can be different from what they are used to. In order to get attention from the teachers, one girl constantly runs around the classroom when being asked to do something. If a teacher follows her she will smile and continue to run as if she is playing a game of run and chase. The teachers have now decided to ignore this behavior and not chase the girl so that she knows that this behavior is not acceptable and teachers will not give her the attention she wants. This has been going on for some time and eventually over time the girl has not been running as much and has started to get used to the routines that are in place in the new classroom.

\section{4) Redirecting the child}

I have seen the teacher's redirect the children a number of times throughout my observation. During the free time that the children have, the staff monitor where the children are what they are doing. One example of redirecting was when a child was misbehaving during circle time. This was with the whole group. The child had been warned several times to stop what he was doing but kept repeating the behaviour and was not listening to what he was told to do. The teacher then removed him from the group and he was asked to wait in a different area of the classroom until circle time was over. Another example of redirecting was when a child was playing in the sand area and purposefully throwing sand on the floor. The teacher saw and immediately said that this area was closed, gave a reason as to why they could not play there anymore and they were then asked to go and play in another area. Another example of redirecting is when a child is misbehaving in one area of the classroom - they are then asked to go and play somewhere else. One child was 
throwing toys in the carpet area. He was asked to move from the carpet area to the quiet area. He was not allowed to play in this area for the rest of the day.

\section{5) Distracting the children}

The children can become very distracted by different things within the classroom due to the wide amount of opportunities for them to play with and other peers. One particular example of distracting the children is during circle time. If the teacher can see that the children are not paying attention or are not interesting in the activity then they will use the distracting strategy to get them to become more engaged.

\section{6) Adjusting the classroom environment}

The classroom layout and environment is changed and adjusted depending on the theme that is going on in the classroom. As a new theme is being taught the teachers will change the resources, manipulative and play tools. This allowed the teachers to work together as a team to use the space effectively in order for them to teach to the best of their ability to use the space and resources efficiently. Through discussion and collaborating with the teacher in my observed class, I helped plan and implemented a new seating plan and table layout which best suits the needs of the students in the class.

\section{7) Adjusting the classroom schedule}

The staff at my observed class is very flexible in changing the classroom schedule to suit the needs of the students. The routine in place allows for centre time, circle time, outdoor play, walks, nap, and meals including lunch and breakfast and various other activities. One example of changing the schedule is when it is not suitable to go outside. The schedule is then changed so that the children can do activities that use large motor skills. When the children seem to have too much energy then the children will do some kind of large motor skill activity such as some dance, song or energetic movement that will help them release energy. The schedule can also be changed when a special visitor comes in. This use of flexibility is highly important for young children and gives them a chance to practice rules that are in place.

\section{8) Time out}

The strategy "time out" is only used after all the other strategies have been tried and failed or if the behaviour is so severe that the child needs to be redirected to time out immediately. The use of "time out" or an additional plan that affects behaviour is rarely used within the classroom.

This works well with the younger aged children, however with older children the teacher would need to address the problem with the child in order to find a solution.

If after all these discipline strategies listed above have been tried but have failed then the teachers would have to move on to a behaviour incident report. This written down chart can show clearly if there is a specific problem that needs to be fixed, such as does this behavior happen at the same time of day, same place, is it the same child involved. All of these hints can give the teachers an idea of the solutions that can be used to solve the issue.

When there seems to be a consistent pattern of behavior from one child then the teacher will discuss with parents and other teachers and decide whether it is necessary to use a "positive behavior intervention and supports action plan". I have seen one example of this plan being put into action while I have been on observation. One boy in the class has continually been misbehaving for the past month. His misbehaviour issues are throwing, hurting other children, not listening or following teacher"s rules. The teachers have been consistent in the way in which they handle these situations. The teachers have used all the strategies listed above in order to try and deal with the problems but unfortunately after time they have had no effect. The parents and other teachers have got involved and have decided to make the boy a plan of action. This plan is child friendly and lists every area of the class schedule. There is a smiley and frown face on the chart under each part of the day (morning meeting, outside play, lunch, free play etc). After each section the teacher brings the child aside and discusses with the child what he has done and whether he should get a smiley face. Other teachers will be assessing his behavior during these times. If the boy gets 3 smiley faces then he will get a reward of some kind.

\section{Theme Three: Rules: Evidence for Rules Being Used with Student Who Exhibits Disruptive Behaviors}

One particular student regularly exhibited disruptive behaviors such as calling out, not following directions and instructions from the teacher as well as disrupting the learning of others during group work activities. As a result the teacher organized a conference with the parents of the student and spoke to the student one on one to establish a cause behind the behaviour as well as find a solution. The result was the construction of an individual behaviour plan with a reward system. The plan involved a point system whereby the student had a sheet, which has the main activities of the day including language arts stations, math stations and morning meeting. There are three behaviour criteria for the student to focus on, which were agreed upon by the student and teacher. These include quiet hands, quiet, feet, quite mouth. These relate to not calling out or shouting during classroom activities (quite mouth), and keeping hands and feet to themselves (quiet hands and feet). Each criterion has a score ranging from zero to three. The teacher working with the student during these activities observes the student's behavior and gives a score out of three for how well they have followed the criteria. This evidence illustrates how not consistently following the classroom rules can lead to disruption of learning and teaching as well as how it can lead to the escalation of minor problems. It also makes the consequences of breaking the rules seem more punitive to the students.

Part of the teacher's classroom behaviour management plan includes student's creating an I-message in response to a conflict that has arisen between two students. The I-message is a powerful way of communicating how certain behaviour or action makes a student feel and as a consequence lets the student whose behavior or action has caused the conflict lets them see how their action are affecting other people. When a conflict between two or more students occurs, then the teacher will ask the students who have been affected by the actions of others whether they have an I-message for that 
person. I saw one example of how this was being used in the classroom when two students were arguing because one of the students had been calling the other student names. This argument escalated from an incident that happened previously in the day when one of the students used a pencil that had been left out on the desk during group work and which belonged to the other student. To avoid this conflict escalating any further the teacher gave them a couple of minutes to calm down and then asked each student to create an I-message which they would say to each other. The first student said "I feel sad when you call me names because it is not very nice", the second student then said "I feel angry when people take my things without asking because they are special to me". Both students then apologized to each other. This is an example of how a self-monitoring technique is used as a direct response to an incident that has happened. I visibly saw how the students calmed down and controlled their behaviour towards each other after the incident had passed.

\section{DISCUSSION}

There are numerous strategies and interventions that a teacher could use in order to maintain control and provide a good behaviour management system. "A strategy is an action taken by the teacher that is intended to stop the disruptive actions and return the student to the academic activities." [4] The strategy given should be based on the teacher's knowledge of what they know about the child, the action or misbehaviour issue and how often it occurs. I have decided to focus on three strategies in detail. These will be the "use of encouraging and reinforcing behavior", "the use of reward" and the "use of I messages" [5].

\section{A. Encouragement and Positive Reinforcement}

One of the most important factors in a well-run classroom is the use of encouragement and positive reinforcement. This strategy links in with the teacher's behaviour and beliefs. If a teacher has high expectations for all of their student's then positive encouragement, feedback and praise will come naturally and the students will often respect you for it and have an appreciation of learning and want to please you. When using positive reinforcement and encouraging the children to learn then the children will be motivated to do well. "The teacher serves as a powerful model in providing examples of ways for students to support each other with words of encouragement, questions for clarification and entry for collaboration" [7]. From this quote we can see the power the teacher has in order to create a positive and comfortable environment for the children to learn. Through the use of positive feedback and encouragement the students could start to model the practices of the teacher and may apply this to their own relationships with peers and others. This effective strategy is one that is crucial to students who need reassurance. If the teacher is constantly providing feedback and encouragement to all, and then an inclusive classroom will be built that will have many advantages for the future.

This theory is based upon three basic components;

1) Identifying the behavior that motivates negative actions,
2) Developing alternatives to this behavior that will provide the student with positive feedback,

3) Reinforcing positive behavior to replace the negative behavior by helping the student change his response to the same stimuli.

The aim of this theory is that after the teacher has recognized the negative behaviour, the teacher will be able to redirect the student's actions by using the same energy in positive rather than negative way.

\section{B. The Use of Rewards}

Feedback and rewards can come in various forms. The strategy stated above can be used as a form of reward. The use of praise and positive reinforcement is one of the most important forms of reward, as praise can be satisfying to students and can affect the quantity and quality of the student's work and performance. The use of verbal praise and informative feedback can "allow students to receive satisfaction for the progress they have made so far, and is a much better way of rewarding rather than using threats or close monitoring" [4]. There are however many arguments against the use of praise and reward systems. It has been said by many that the over reliance and over use of verbal praise may become ineffective and unhelpful.

However surprising this is, many teachers still use this strategy throughout their teaching as a tool for creating a positive and manageable classroom environment. Ginott (1972) found that praise could be categorized into two types; appreciative praise and evaluative praise [7]. When giving praise it is important that teachers do not evaluate personality or judge character. This praise would be appreciative. This clearly shows that the use of praise as a type of reward should only be used if it is effective and makes a difference to the dynamics of the classroom and the behaviour that can be seen within it. Some examples given by Burden include rewards delivered in various ways such as -grades, spoken and written praise, activity rewards and special privileges (play games, use equipment), symbolic rewards (honour rolls, posting good papers), material rewards and teacher rewards (opportunities to work with teacher).

\section{The Use of I Messages}

The "I message" is used for elementary aged children that focuses on the extent of the problem and provides a solution. It helps children understand the importance of social and emotional development as they are learning to become "good'friends to others. The message would include a description of the behaviour, how it affects the rest of the class or individual and how the teacher feels about this. This strategy gives the students a chance to take responsibility of their own behavior by understanding what they have done and how they have affected others, and therefore correct the situation.

\section{Evaluation of All Three Themes}

We will now discuss and evaluate our three themes. As you may have noticed we have three major themes. Under each major theme we have sub themes. These themes come under the main umbrella theme of classroom management. We will now sum up what we have found under each main theme and how I have seen this in my school observations: 


\section{E. Teacher Behavior}

This theme has been a very interesting one to research and find more about. I have been lucky enough to see 2 different classes in an International school. We have discussed how we thought that the behaviour that the teacher showed towards the children made a huge impact upon their overall behaviour There seemed to be much more respect for the teachers even though the teachers and students were on the same authority level. We wanted to see how aspects of the teacher's behaviour affected the way in which the children behaved and responded to them. We strongly agree with Wong and Wong when they say that the when the teacher does not want to learn then they will be setting up a negative environment where the children will not want to learn either. We suggest that teachers should be enthusiastic in general but especially when teaching new topics.

The management style of the teacher has a huge impact on the way the children will behave. We found that there are three types of management suggested by Levin and Nolan [1]. These are student direct management, collaborative management and teacher directed. Although Levin and Nolan imply that a teacher can use only one or the other teacher management strategies [1], we disagree. We have found within our case studies observations that a teacher can provide a mixture of teacher management strategies and still show effective teacher management. In the preschool class there are 2 teachers who all use a mixture of management strategies. This has been interesting to see as the students still seem to respond in a similar way to all.

The next sub theme under teacher behaviour is relationships. The relationships that teachers build with the students, families and colleagues will be ones that may last a lifetime. The relationships that you build with your students will have a huge impact on their academic achievement as well as the way in which they behave. In our background research we found some interesting facts that affect the way teachers and students form relationships. We agree with Cangelosi (2008) as he states that the language that the teacher uses can affect the relationship that is made [3].

Our final sub section under teacher behavior is labeling. We felt this was closely linked to teacher behaviour in a number of ways. Firstly this links in closely with positive relationships. If the teacher tends to favour some students over others then the students in the class may pick up on this and may act differently [13]. This clearly shows that the way in which the teacher behaves and acts towards the students will have a significant impact upon their enjoyment of learning, their behaviour, the way in which they learn and their overall academic achievement. One way in which this is eliminated is by not to let students know what level or grade they have and showing respect for all the children in the class.

\section{F. The Use of Practical Strategies}

The next theme that we wanted to look at in more detail is the use of practical strategies and interventions that reduce or stop the problems of misbehaviour in the classroom. There are many strategies that teachers use and these may in fact be linked to the teacher's behaviour and management style. These strategies are encouraging and reinforcing behavior, the use of rewards and the use of I messages.

We certainly agree that positive reinforcement and encouragement is crucial as a practical strategy that should always be present in the classroom [14]. Encouraging the students and reinforcing them for appropriate behaviour is essential in every classroom and it is a way that positive relationships can be made between teachers and students. We agree with Herrell (2007) who states that by creating a positive inclusive environment for students with lots of positive reinforcement and encouragement, you are setting up positive examples and building strong relationships for the future [6]. It is true that this behaviour by the teacher should be consistent especially for younger grades as they are just getting used to the rules and procedures of their classrooms.

Positive reinforcement could be used as a type of a reward in a classroom [13]. Verbal praise and feedback can allow students to receive satisfaction and worth in themselves and the work they have done [14]. However in our background we did find out that too much praise might not be effective. We found that it can be a "hook" for some children and teachers may be handing out praise for anything making it not so meaningful and powerful when one student does receive it.

There are however an example of other rewards that can be delivered in a number of different ways. We have seen a variety of different ways that rewards can be given in many different classrooms.

The next theme we discussed was the use of "I messages". As described earlier the "I message" is used to focus on the problem and to find a solution. We were surprised to see this strategy used even with the much younger age of preschool. The strategy asks children to take responsibility of their own behaviour and to take logical consequences for their own behaviour. Although originally we were not sure if this was appropriate for children as young as three to be taking such a big responsibility for their own behaviour we realized from our observations that it may be crucial and a good start for the future. This method is very effective as it creates a way that the teachers can be prepared in order to hopefully eliminate misbehaviour before it occurs.

\section{G. Rules}

The final theme we chose to look at was rules. We felt that this was very useful to look at because it is one of the fundamental aspects of classroom management and specifically relates to managing the behavior of students in the classroom [15]. In the first part of this theme we looked at the construction of rules and how they contribute to reducing incidents of misbehaviour. We agree with Levin and Nolan (2010) who stated that rules provided a structured learning environment and sense of security for students who exhibit disruptive behavior [1]. We made a connection between this idea and the ideas of Wong and Wong, (2009) who point out that rules provide consistency in the classroom [2]. It is evident from our observations that rules do provide the security that students need in the classroom.

The next part of the rules theme we focused on was self-monitoring behaviour. We strongly agree with Jones, (2004) who suggested that rules should be thought of as a 
way to encourage students to choose appropriate behaviour rather than being seen as a means of punishment for bad behavior [8]. This was evident in the self-monitoring techniques such as behaviour reflection sheets we saw in our classrooms, which seemed to help reduce misbehaviour because it encouraged students to think about the causes and consequences of their actions. It is also clear that this is a useful way to aid in children's moral development [12], [13].

From looking at these three themes we have found three main common aspects amongst them. The first common aspect is that they are all very student centered. For example in looking at theme one we discovered that if a teacher's management style is student centered and the teacher has a positive relationship with all students then incidents of misbehavior are reduced. In theme two we discovered that if the teacher uses strategies such as encouragement and reinforcing positive behaviour then it creates a more positive learning environment in which students are more willing to learn. When looking at theme three we found that the use of consistent rules and self-monitoring behaviour is more effective at reducing misbehaviour because students will eventually become autonomous in managing their own behaviour. This is a very student centered approach.

Another common aspect that appears across our three themes is constancy. In theme one we discovered that the management style and relationships built between teacher and student needs to be consistent and apparent from day one. The strategies and interventions outlined in these two need to be applied consistently in order to be effective. In our final theme we found that rules need to be reinforced consistently to ensure that students understand them clearly and follow them regularly.

\section{CONCLUSIONS}

Although we found these themes to be effective, they should not be viewed as universal themes to be used at all times. This is due to every student and every class being different and what works with one student or class may not work with another.

Overall I have had very positive experiences in my observations in the school. I have gained great insight into how the International CBSE kindergarten and primary system works and have taken a great deal of pedagogical experiences and strategies from and hope to use in the future. I believe that if the teacher has strong purposeful beliefs, high expectations, a positive friendly manner and an enthusiastic and engaging approach to teaching and learning then the classroom will be set up for students to succeed whatever the situation or place. Similarly we feel that using self monitoring techniques and specific strategies such as behaviour reflections is easier with a smaller class size because the teacher would have more time to plan specific self-monitoring materials which can be tailored to suit the specific behaviour management needs of each student. However we think that it would be possible to use these strategies in schools especially I-messages and teaching students to reflect and control their own behaviours, which would be useful to teach as part of a wider social and emotional aspects of learning curriculum. In light of this we propose the above similar study for future comparative research on classroom management strategies in Malaysian schools.

\section{REFERENCES}

[1] J. Levin and F. J. Nolan, Principles of Classroom Management, Sixth edition, Boston, Pearson Education Inc., 2010.

[2] K. H. Wong and T. R. Wong, "The first days of school, How to be an effective teacher," Mountain View California, Harry K. Wong Publications Inc., 2009.

[3] J. S. Cangelosi, Classroom Management Strategies, Gaining and Maintaining Students' Cooperation, New Jersey, USA: John Wiley and sons Ltd., 2008.

[4] P. Burden, Classroom Management, Creating a Successful K - 12 Learning Community, New Jersey, John Wiley and sons Ltd., 2006.

[5] C. J. Hardin, Effective Classroom Management, Models and Strategies for Today's Classroom, 3rd edition, Boston, USA; Pearson publications, 2012

[6] A. L. Herrel and M. Jordan, 35 Classroom Management Strategies, Promoting Learning and Building Community, New Jersey, Pearson Merrill Prentice Hall, 2007.

[7] M. C. Evertson and T. E. Emmer, Classroom Management for Elementary Teachers, New Jersey, USA: Pearson Education Ltd., 2009.

[8] V. Jones and L. Jones, Comprehensive Classroom Management, Creating Communities of Support and Solving Problems, Boston Masachussets, USA, 2004

[9] L. K. Lane, M. H. Menzies, L. A. Bruhn, and M. Crnobori. (2010). Managing Challenging Behaviors in Schools: Research-Based Strategies That Work. [Online]. Available: http://www.pensu.eblib.com.ezaccess.libraries.psu.edu/patron/FullRec ord.aspx? $=593772$

[10] S. Bentham, A Teaching Assistant's Guide to Managing Behaviour in the Classroom, Oxon, UK, Routledge, 2006.

[11] H. Lotfabadi. (2008). Criticism on Moral Development Theories of Piaget, Kohlberg, and Bandura and Providing a New Model for Research in Iranian Students' Moral Development. [Online]. Available: http://www.sid.ir/en/VEWSSID/J_pdf/97420082403.pdf

[12] B. S. Nissman, Teacher Tested Classroom Management Strategies, New Jersey, USA, 2006.

[13] The Prevention Research Center. (2012). [Online]. Available: http://www.prevention.psu.edu/projects/PATHSCurriculum.html

[14] K. M. W. Trochim. (2006). Qualitative Measures. [Online]. Available: http://www.socialresearchmethods.net/kb/qual.php

[15] H. C. Wolfgang, Solving Discipline and Classroom Management Problems, Methods and Models for Teacher's Today, New Jersey, USA, John Wiley and Sons Ltd., 2009.

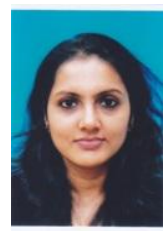

Priya Vijayan is a lecturer in Segi University, Malaysia With nearly a decade of teaching experience, she has enormous experience in early childhood education, and in special needs education. She is a qualified psychotherapist and counselor. She is a well-loved lecturer, with innovative curriculum delivery, and is highly rated by students feedback. She is also involved in coordinating modules and in community activities. Priya has published relevant educational papers in indexed peer reviewed journals. 